\title{
The reconstruction of psychiatric services after the liberation of Kuwait
}

\author{
Mohammed Aly ARef, Chairman of Psychiatry, Kuwait Psychological Medicine \\ Hospital, PO Box 4081, Safat, Kuwait
}

In this paper I describe my experience of restructuring psychiatric services after the Iraqi invasion. It is difficult, if not impossible, to find words to describe the frustration, bitterness, sorrow and disappointment in seeing the collapse of a service that had been built up by the strenuous efforts of psychiatrists.

I should like first to summarise service provision before the invasion. The main psychiatric hospital had a capacity of 567 beds with an average occupancy rate of $75-80 \%$. It had an out-patient facility with an average of $100-120$ consultations daily. It catered for all medico-legal cases and was the main facility for both undergraduate and postgraduate teaching. Manpower comprised 63 psychiatrists, of whom 17 were consultants, and four of them belonged to the Medical College. We had 19 extramural services that covered the whole of Kuwait.

In the early days of the invasion all medico-legal patients were released. The army stripped the addiction facility, and during the withdrawal damaged it beyond any prompt repair. The mortality rate was high; families preferred to take away their patients whenever feasible. The staff gradually left and the hospital became nearly deserted. The Medical College was no luckier; all the staff left and its equipment and books were all removed.

As the confrontation became unavoidable and the war imminent, his Excellency the Minister of Public Health asked the Heads of Departments outside the country to request emergency teams to be on standby. On 12 January 1991, the teams were flown to Saudi Arabia where we stayed until 3 March when we returned to liberated Kuwait. I had the honour to head the psychiatric team of four. On arrival, all that was left was a facility that was short of everything, including food, water supply, clothes and electricity. The seven doctors who were left and preferred to stay, struggled to run the hospital managing 178 in-patients, mostly chronic. Two of my senior colleagues who outstandingly and boldly had managed the hospital during the occupation found no alternative but to leave on 16 January 1991, and the hospital was reduced to chaos.

Our team, with the remaining seven doctors and a consultant who joined later, worked day and night to improve conditions and restructure what was left. His Excellency the Minister of Public Health personally took the responsibility of handling the situation. Indeed, he is credited for the support both morally and physically he generously gave us.

Soon the hospital was overwhelmed by an influx of medico-legal cases and patients suffering from post traumatic stress disorders with reported torture. Gradually the number of patients suffering from outpatient consultations increased - doubling, trebling and quadrupling in number. In a couple of months the department had to run postgraduate training for family doctors and general practitioners.

In the next few months one consultant from the Medical College returned and was asked to run undergraduate teaching. Ultimately, students who returned received both theoretical and clinical teaching by one consultant from the Medical College and our four consultants.

Under the auspices of His Highness the Emir and Crown Prince, His Excellency the Minister of Public Health took the initiative to develop a centre for the management of post traumatic stress disorders. Subsequently our hospital became directly involved with this centre. Expertise and specialists in this field were recruited to work with our staff in this centre.

The hospital now has the following services:

(a) 377 functioning beds with an average occupancy rate of $95-105 \%$

(b) an out-patient clinic running with average of 200-230 patients daily draining the whole country for five days a week

(c) consultations for other hospitals all over the country

(d) a service for the prisoners, paediatric department and Institutes belonging to the Ministry of Social Affairs as well as schools for the handicapped run by the Ministry of Education

(e) assessment and management of psychiatric medico-legal cases over the country

(f) referral of military and police psychiatric cases

(g) post-graduate teaching and training

(h) management of addiction and substance abuse

(i) undergraduate teaching (both theoretical and clinical) with the Chairman of Psychiatry, Medical College

(j) the PTSD centre. 
At present we are planning to re-open and expand the rest of the 19 extramural services which existed before the invasion.

Without the enthusiasm and hard work of my colleagues and the staff it would have been impossible to bring the psychiatric service to its present shape in such a short period.

I thank my colleagues inside and outside the country, the international organisations and their affiliates who have lent me their support during that critical period, and especially His Excellency the Minister of Public Health, Dr Abdul Wahab Al-Fowzan, for his unlimited support, patience and encouragement during the invasion, during the war and after liberation. My thanks also go to my colleagues Dr Magda El-Badramany, Dr Abdel Rahman Fawzy, Dr Essam El-Ansary and Dr A. Fido, consultant psychiatrists, for their efforts and support in the re-establishment of the services.

\title{
Conference briefing
}

\section{Residential scientific conference for registrars and senior house officers in psychiatry}

\author{
O. JunAID, Chairman, Collegiate Trainees' Committee
}

Fifty junior trainees attended the conference which was held at Warwick University between 9 and 11 July 1992. For many trainees this was the first example of the Royal College of Psychiatrists working for trainees. The highlight was an address by $\mathrm{Dr}$ Fiona Caldicott, the Dean. She discussed the effects of recent White Papers and the consequent changes in the National Health Service. Opening up a debate on a variety of issues of direct relevance to trainees and training, her address turned into an interactive session. Trainees expressed their worries and concerns, particularly about the effect of European legislation on the movement of doctors and the effect this would have on training in this country.

The rest of the conference followed a pattern which has been successful for the senior registrar conferences. There were day-long sessions on Friday on effective presentation skills, witness skills and succeeding in interviews. The following day there were halfday workshops on research methodology, management and writing scientific papers.
Research methodology was a particularly popular workshop. Professor Patricia Casey, of University College Dublin, conducted the workshop. Trainees recognised the value of undertaking pre-membership research but they also expressed concern at the lack of facilities for supporting trainees (particularly in peripheral posts) involved in research projects.

The meeting provided an opportunity for trainees from a variety of rotational training schemes from all over the United Kingdom to meet and share views and ideas. Trainees expressed a desire to form closer links between rotational training schemes. The Conference offered them the opportunity of comparing and contrasting training experiences and to begin to form links and establish relationships which might eventually lead to collaborative ventures.

Feedback at the plenary session was generally positive. Most wished to return next year, even to the same venue, as two days was too short to attend all of the workshops. 